\title{
The effect of curing conditions on the mechanical properties of SIFCON
}

Kubilay Akçaözoğlu (Main Author and Corresponding Author)

Department of Civil Engineering, Faculty of Engineering, Niğde Ömer Halisdemir University, 51000, Niğde (Turkey)

ozoglu@ohu.edu.tr

\section{Adem Kıllı}

Department of Civil Engineering, Faculty of Engineering, Niğde Ömer Halisdemir University, 51000, Niğde (Turkey)

ademkilli94@gmail.com

Manuscript Code: 14030

Date of Acceptance/Reception: 25.02.2021/16.05.2020

DOI: $10.7764 /$ RDLC.20.1.37

\begin{abstract}
In this study, the effect of curing conditions on the mechanical properties of slurry infiltrated fiber reinforced concrete (SIFCON) was investigated. For this purpose, SIFCON samples containing $4 \%$ and $8 \%$ steel fiber with two different aspect ratios were produced. The samples were subjected to three different curing types, namely standard, dry and accelerated curing methods. Ultrasonic wave velocity, flexural strength, fracture toughness, compressive strength, impact resistance and capillary water absorption tests were performed on the samples. The highest flexural strength was found to be achieved in the samples with an aspect ratio of 55 and a content of $8 \%$ steel fiber. The most suitable curing method was determined as the standard curing method and the best flexural strength was achieved at the rate of $8 \%$. According to the test results, the best strength properties were achieved in the samples exposed to the standard curing method. In addition, the samples exposed to the accelerated curing method showed satisfactory values. The accelerated curing method can be used as an alternative in SIFCON production especially in applications requiring mass production.
\end{abstract}

Keywords: capillary water absorption, compressive strength, curing conditions, flexural strength, impact resistance, SIFCON.

Introduction

Concrete is one of the most widely used construction materials due to its advantages such as high compressive strength, durability and economic efficiency (Yoo et al., 2018). Despite its many advantages, concrete also has various disadvantages in terms of tensile, fatigue, wear, impact, sliding, load bearing strength after cracking, deformation and energy absorption capacity (toughness). The technical properties of concrete can be improved with the addition of various materials to develop and strengthen these disadvantages. Brittleness is another disadvantage of concrete and increasing ductility is considered as a solution to this problem (Taşdemir et al., 2004; Topçu and Boğa, 2005).

Thus, using fiber in concrete, which increases both the flexural strength and the energy absorption capacity, is one of the best resolutions for the brittleness issue. However, as the amount of fibers in the mixture increases, the workability of the concrete is adversely affected, therefore the proportion of fiber that can be added to the concrete is generally 1 3\% (Ijpek et al., 2012; İpek et al., 2014; Hajar et al., 2004) Nevertheless, there are various special composites, such as slurry infiltrated fiber reinforced concrete (SIFCON), that are produced with a higher steel fiber volume ratio (Wang, 1994). SIFCON, which was produced by Lankard (1984), is a composite that contains high rate fiber and a cement based slurry with superior mechanical properties such as high compressive, tensile, shear, flexural and toughness values (Yoo et al., 2018; Homrich \& Naaman, 1987; Naaman et al, 1992a).

SIFCON consists of fibers that are randomly distributed and interlocked, a feature that makes it is similar to fiber reinforced concrete (FRC). However, FRC has $1 \%$ to $3 \%$ fibers, while SIFCON contains $5 \%$ to $30 \%$ fibers by volume (Hajar et al., 2004; Elevarasi and Savarana, 2018; Beglarigale et al., 2016). The composition of the matrix is another major difference between the two concrete types. In SIFCON production, unlike FRC, flowing consistency slurry is used. In addition, SIFCON is produced by infiltrating cement slurry into the fibers that have been previously placed in the mold. This difference in casting method is another feature that distinguishes SIFCON from FRC (Rao et al., 2010).

SIFCON is a new construction material that has a high energy-absorption capacity and is used in application areas such as defense structures and safe vaults (Schneider, 1992; Naaman et al., 1991; Naaman et al., 1992b). Due to its superior toughness feature, the potential usage areas of SIFCON are industrial floors, pavements, strengthening and retrofitting works, structures that are exposed to impact loads (Naaman et al., 1992a), seismic resistant structures (Murakami and Zeng, 1998; Wood, 2000; Homrich and Naaman, 1987) and explosion resistant military structures (Schneider, 1992). In addition, it is used as slabs on elastic grounds where ductility is an issue (Beglarigale et al., 2016). The mechanical 
properties of SIFCON depend on the fiber and slurry properties such as fiber type and volume, aspect ratio, alignment, embedment length, fiber-matrix bond properties, modulus of elasticity and the compressive strength of the slurry (Lankard and Newel, 1984; Naaman et al., 1987; Stiel et al., 2004; Tuyan and Yazıcı, 2012; Ipek et al., 2014). The maximum fiber volume depends on the fiber type and the vibration needed for proper compaction. Shorter fibers can be denser than the longer fibers, and higher fiber volumes require proper placement and careful vibration (Lankard, 1984; Beglarigale et al, 2016).

The tensile strength and fracture toughness of SIFCON increases with the increase in the fiber content (Wecharatana \& Lin, 1992). It has been stated that with the increase of the steel fiber content and aspect ratio, the energy absorbed until SIFCON samples break increases and the material exhibits more ductile behavior (Shan \& Zhang, 2014). As the matrix strength increases, the adherence of the fiber-matrix interface bond also increases. In addition, increasing the embedding length results in increased toughness. (Shannag et al., 1997). SIFCON possess greater ductility and energy absorption capacity and has a higher resistance to cracking and spalling effects than FRC specimens (Thirugnanam et al., 2001). Therefore, it has a lot of potential for applications in structures subjected to impact and dynamic loading (Rao et al., 2010).

In order to improve the mechanical properties of SIFCON, mineral additives such as fly ash, silica fume (SF) and slag are used by replacing the cement in the slurry (Lin et al., 2014; Yazıcı et al., 2006; Yazıcı et al., 2010; Köksal et al., 2008; Tuyan and YazıcI, 2012; Beglarigale et al., 2016; Elavarasi, 2018; Ipek et al., 2014; Jung et al., 2017). It is indicated in the literature that, SIFCON slab elements exhibit excellent behavior in terms of flexure and punching shear when compared to FRC, reinforced cement concrete and plain cement concrete slabs (Rao et al., 2005; Rao et al, 2008).

Wecharatana and Lin (1992) stated that the compressive and flexural tensile strengths of SIFCON samples containing 4$10 \%$ hooked steel fiber increased with the increase in the fiber content of the samples. In a study conducted by Bayramov et al. (2002) the effects of steel fibers on high performance concretes were examined and it was determined that the energy absorbed until fractures increased and the material showed more ductile behavior with the increase of steel fiber content and aspect ratio. Fiber adherence increases when the slurry strength and fiber aspect ratio are increased and proper curing is applied (Tuyan \& Yazıcı, 2012). In recent years, the number of studies on the mechanical properties of SIFCON, such as fiber content, aspect ratio, slurry properties, and slurry strength, have increased. Nevertheless, the studies on the performance of SIFCON exposed to different curing conditions are limited. Yet, curing is one of the most significant factors that affects the strength and durability of concrete. Applying optimum curing conditions to concrete during the first days is very important for increasing strength and reducing bleeding and plastic shrinkage. Additionally, curing conditions significantly affect the fiber-matrix interface bond (Tuyan \& YazıcI, 2012).

The main aim of this study was to investigate the effect of three different curing methods, namely standard, dry and accelerated curing, on the mechanical properties of SIFCON through experimental studies. Two types of steel fibers were used in two different proportions to examine the effect of steel fiber volume and fiber aspect ratio on strength. Additionally, in the slurry mixture, $10 \%$ of SF and $20 \%$ of slag were replaced by cement in order to increase strength and save cement.

\section{Experimental study}

In this study, CEM I 42,5 R Portland cement, which was in conformity with the TS EN 197-1 standard (2012), was used. The specific gravity of the cement used was 3.10, while its Blaine specific surface was $3495 \mathrm{~cm}^{2} / \mathrm{gr}$. Granulated blast furnace slag (GBFS) and SF were used as the mineral additives. The GBFS, which was in compliance with the TS EN $15167-$ 1 standard (2006), was obtained from the Iskenderun facilities of Adana Cement and had a specific gravity of 2.87 and a specific surface of $5180 \mathrm{~cm}^{2} / \mathrm{gr}$. The SF was obtained from the Antalya Plant of the Eti Elektrometalürji Inc. and had a specific gravity of 2.30 and a specific surface of $200000 \mathrm{~cm}^{2} / \mathrm{gr}$. The chemical properties of the cement, SF and GBFS are given in Table 1.

\begin{tabular}{lccccccccccc}
\multicolumn{10}{c}{ Table 1. Chemical properties of the cement, SF and GBF. (Self-Elaboration). } \\
\hline Oxide (\%) & $\mathrm{SiO}_{2}$ & $\mathrm{Al}_{2} \mathrm{O}_{3}$ & $\mathrm{Fe}_{2} \mathrm{O}_{3}$ & $\mathrm{CaO}$ & $\mathrm{MgO}$ & $\mathrm{Cl}$ & $\mathrm{SO}_{3}$ & $\mathrm{Na}_{2} \mathrm{O}$ & $\mathrm{K}_{2} \mathrm{O}$ & LOI \\
\hline Cement & 21.16 & 5.79 & 2.65 & 60.61 & 1.28 & 0.01 & 3.10 & 0.33 & 0.52 & 1.13 \\
SF & 91.92 & 0.42 & 0.20 & 2.06 & 3.28 & 0.03 & 0.83 & 0.55 & 2.58 & 1.68 \\
GBFS & 38.20 & 11.10 & 0.83 & 38.96 & 6.88 & -- & 0.52 & -- & -- & 2.27 \\
\hline
\end{tabular}

Abrasion and weather resistant silica sand with a maximum grain size of $0.5 \mathrm{~mm}$, water absorption capacity of 0.64 and a specific weight of 2.64 , was used as aggregate. A polycarboxylic ether based high water reducing superplasticizer 
additive, in compliance with the TS EN 934-2 standard (2013), was used in order to ensure workability with the mixtures. Steel fibers that were compliant with TS EN 14889-1 standard (2016) and had a low carbon content, hooks on both ends and two different aspect ratios (I/d) were used. The properties of the steel fibers are given in Table 2.

\begin{tabular}{lcc}
\multicolumn{3}{c}{ Table 2. Properties of the steel fibers. (Self-Elaboration). } \\
\hline Fiber type & Type I & Type II \\
\hline Length $(\mathrm{mm})$ & 30 & 30 \\
Diameter(mm) & 0.55 & 0.75 \\
Aspect ratio (I/d) & 55 & 40 \\
Tensile strength (MPa) & 1500 & 1200 \\
Number of fibers per kg (piece) & 16750 & 9000 \\
\hline
\end{tabular}

\section{Mixture proportions}

High-strength slurry was used in the preparation of the samples as slurry strength significantly affects the fiber-matrix interface bond. The water/binder ratio of the slurry was determined as 0.3 . The workability of the slurry was measured in accordance with the TS EN 1015-3 / A2 standard (2007) with a mini flow test and flow diameter was measured as 37 $\mathrm{cm}$. The mixture compositions are presented in Table 3.

\begin{tabular}{lc}
\multicolumn{2}{c}{ Table 3. Mixture compositions. (Self-Elaboration). } \\
\hline Materials & Quantities (kg) \\
\hline Cement & 700 \\
GBFS & 200 \\
SF & 100 \\
Silica sand & 887 \\
Water & 300 \\
Superplasticizer & 21 \\
\hline
\end{tabular}

The fresh unit weight, compressive strength, flexural strength and ultrasonic pulse velocity (UPV) values of the samples that were prepared from the slurry and did not contain steel fibers were $2310 \mathrm{~kg} / \mathrm{m}^{3}, 79.63 \mathrm{MPa}, 17.0 \mathrm{MPa}$ and 4851 $\mathrm{m} / \mathrm{s}$, respectively. Four different SIFCON groups were prepared by using two different types of steel fibers with a volume of $4 \%$ and $8 \%$. In order to investigate the effects of curing conditions on the mechanical properties of SIFCON, three different types of curing methods namely, standard water curing, dry curing and accelerated curing, were used. The notations of the samples used in the experiments are given in Table 4.

\begin{tabular}{lcccc}
\multicolumn{5}{c}{ Table 4. Notations of the samples. (Self-Elaboration). } \\
\hline Aspect ratio & \multicolumn{3}{c}{55} & \multicolumn{3}{c}{40} \\
\hline Fiber amount & $4 \%$ & $8 \%$ & $4 \%$ & $8 \%$ \\
Standard curing & S55-4 & S55-8 & S40-4 & S40-8 \\
Dry curing & D55-4 & D55-8 & D40-4 & D40-8 \\
Accelerated curing & A55-4 & A55-8 & A40-4 & A40-8 \\
\hline
\end{tabular}

\section{Sample preparation and testing methods}

For the preparation of the SIFCON samples, firstly the predetermined amount of steel fibers was placed homogeneously in the sample molds. Then, the prepared slurry mixture was poured onto the steel fibers in the mold. During the slurry casting, partial vibration was applied by tapping the mold with a plastic mallet. The samples were demolded after 24 hours and then exposed to standard water curing, dry curing and accelerated curing. Standard curing was carried out in the curing pool at $20 \pm 2{ }^{\circ} \mathrm{C}$, dry curing was conducted in a curing cabin with a temperature of $22 \pm 2{ }^{\circ} \mathrm{C}$ and $65 \%$ humidity rate and accelerated curing was performed in accordance with the TS 3323 standard (2012) by keeping the sample in the curing tank in water at boiling temperature for 3.5 hours \pm 5 minutes.

Unit weight, flexural strength, compressive strength, UPV, impact resistance and capillary water absorption tests were carried out on the samples. The experiments were carried out at the end of 28 days of curing for the standard and dry cured samples, and at the end of the accelerated curing process for the accelerated samples. The dry unit weights of the samples were determined by using cubic samples of $71 \times 71 \times 71 \mathrm{~mm}$ dimensions and calculated based on the average of three samples. 
In order to determine the UPV values of the samples two probes transmitting and receiving $55 \mathrm{kHz}$ sound waves were placed on opposite surfaces of the samples and the sound transmission time $(t, \mu s)$ was measured by applying the direct transmission method. The probes were replaced and the second measurement was performed for each sample. The average of these two measurements were taken and the sound velocity (Vs, $\mathrm{m} / \mathrm{sec}$ ) was calculated by using $\mathrm{Vs}=\mathrm{L} \backslash \mathrm{t}$.

In order to determine the flexural strength of the samples, 30x60x300 mm beam samples were used (Figure 1). The flexural strength test was carried out in accordance with the TS EN 14651 standard (2008) to deflection from the midpoint of the beam samples to $0.05-0.1 \mathrm{~mm} / \mathrm{min}$. Within the scope of this test method, the samples were supported at a distance of $20 \mathrm{~mm}$ from the edge points, and flexural tests were carried out by simple beam method by loading from the center of the beam from a single point. Three samples were used for each mixture and the values obtained were averaged.

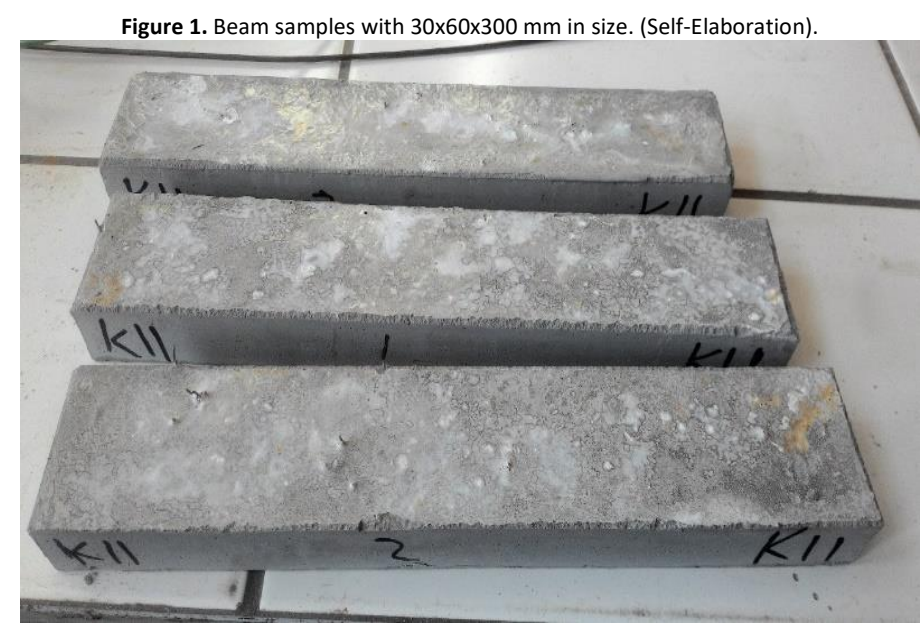

In order to determine their compressive strength $71 \times 71 \times 71 \mathrm{~mm}$ sized cubic samples were prepared and subjected to a uniaxial pressure test in accordance with the TS EN 12390-3 standard (2010). The experiments were carried out on a $3000 \mathrm{kN}$ capacity pressure instrument with a loading speed of $0.6 \mathrm{MPa} / \mathrm{sec}$. Three samples were used for each mixture and the obtained compressive strength values were averaged.

The flexural strength and deflection amounts of the samples were used to determine fracture toughness. For this purpose, the deflection amounts that corresponded to the instantaneous load values were measured with the comparator placed in the lower middle part of the sample. The toughness values of the samples were determined by calculating the area under the load deflection curve in accordance with ASTM C1018 (1989).

An impact resistance test was carried out on 64 × $150 \mathrm{~mm}$ cylindrical samples in accordance with ACl 544 (1988) using a modified proctor test set that is used in geotechnical engineering (Figure 2). Within the scope of this test method, a $4.5 \mathrm{~kg}$ mass was dropped from a $45 \mathrm{~cm}$ height to the midpoint of the samples with a free fall movement. The load transfers between the falling mass and the cylindrical sample were realized with the help of a steel ball $63.5 \mathrm{~mm}$ in diameter. Due to the high impact resistance of the SIFCON samples, there was no cracks in the samples. For this reason, the impact test was carried out with a constant 2500 drop motion on each sample. After the 2500 drop was applied, the diameter of the circular indentation formed on the samples were measured and the amount of the steel ball submerged on the surface of the sample was calculated in a similar way to the Brinell hardness test method, which is used to measure the surface hardness of metals. The indentation amounts were calculated with Equation 1 . The impact resistance test was applied to two samples of each SIFCON mixture and the indentation amounts were averaged.

$$
f=\frac{D}{2}-\frac{1}{2} \sqrt{D^{2}-d^{2}}
$$
$\mathrm{f}$ : indentation amount $(\mathrm{mm})$
$\mathrm{D}$ : ball diameter $(\mathrm{mm})$
$\mathrm{d}$ : measured circle diameter $(\mathrm{mm})$ 


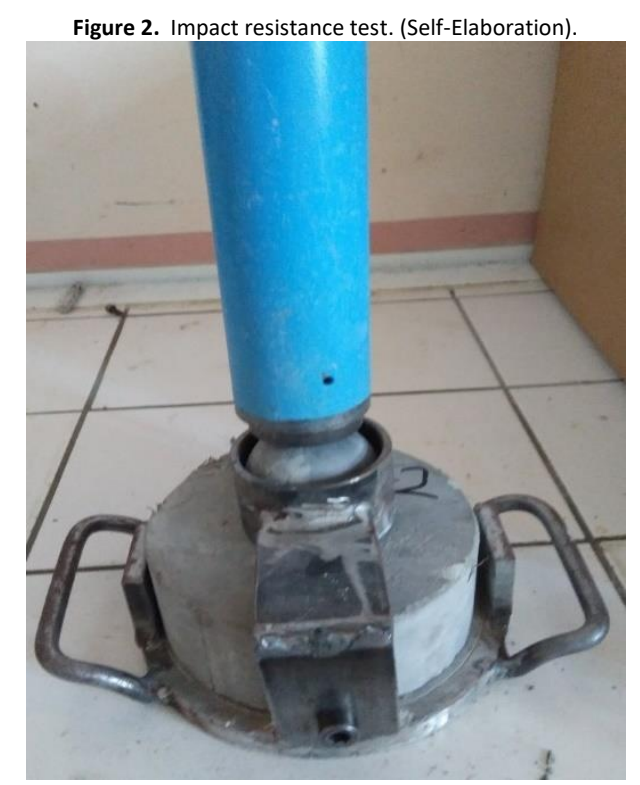

A capillary water absorption test was carried out on cubic samples $71 \times 71 \times 71 \mathrm{~mm}$ in diameter in accordance with the TS EN 772-11 standard (2012). The capillary water absorption coefficients were calculated by measuring the water absorption amounts of the samples at 1, 4, 9, 16, 25, 36, 49 and 64 minutes. This experiment was performed on three samples and the values obtained were averaged.

\section{Results and discussion}

The test results of unit weight, UPV, flexural strength, toughness, compressive strength, impact resistance and capillary water absorption tests performed on the samples are given in Table 5. Samples were coded using the variables curing methods (standard, dry and accelerated), aspect ratios (55 and 40 ) and fiber amount ( $8 \%$ and $4 \%$ ).

\begin{tabular}{lccccccc}
\hline $\begin{array}{l}\text { Sample } \\
\text { code }\end{array}$ & $\begin{array}{c}\text { Unit } \\
\text { weight } \\
\left(\mathrm{kg} / \mathrm{m}^{3}\right)\end{array}$ & $\begin{array}{c}\text { UPV } \\
(\mathrm{m} / \mathrm{s})\end{array}$ & $\begin{array}{c}\text { Flexural } \\
\text { strength } \\
(\mathrm{MPa})\end{array}$ & $\begin{array}{c}\text { Toughness } \\
(\mathrm{Nm})\end{array}$ & $\begin{array}{c}\text { Compressive } \\
\text { strength } \\
(\mathrm{MPa})\end{array}$ & $\begin{array}{c}\text { Impact } \\
\text { resistance } \\
(\mathrm{mm})\end{array}$ & $\begin{array}{c}\text { Capillary water } \\
\text { absorption } \\
(\mathrm{cm} / \mathrm{s})\end{array}$ \\
\hline S55-4 & 2381 & 3918 & 30.00 & 35.74 & 98.23 & 6.30 & 0.0384 \\
D55-4 & 2311 & 4012 & 22.64 & 20.19 & 76.10 & 5.51 & 0.1425 \\
A55-4 & 2472 & 4093 & 23.23 & 27.65 & 68.46 & 6.11 & 0.0384 \\
S55-8 & 2570 & 3923 & 38.28 & 46.01 & 96.25 & 4.33 & 0.0159 \\
D55-8 & 2512 & 4093 & 25.59 & 34.30 & 77.20 & 4.92 & 0.1207 \\
A55-8 & 2624 & 4080 & 25.35 & 34.60 & 66.38 & 5.44 & 0.0393 \\
S40-4 & 2370 & 4134 & 22.75 & 15.91 & 110.55 & 6.46 & 0.0367 \\
D40-4 & 2344 & 4482 & 21.33 & 16.77 & 100.00 & 6.57 & 0.0503 \\
A40-4 & 2430 & 4152 & 19.69 & 14.54 & 73.43 & 6.45 & 0.0337 \\
S40-8 & 2633 & 4267 & 28.60 & 32.28 & 104.46 & 4.98 & 0.0294 \\
D40-8 & 2603 & 4235 & 25.86 & 24.83 & 92.04 & 5.27 & 0.0688 \\
A40-8 & 2600 & 4147 & 23.68 & 28.60 & 72.20 & 5.69 & 0.0420 \\
\hline
\end{tabular}

\section{Unit weight}

When Table 5 is examined, it can be seen that the unit weights of the samples varied between $2311 \mathrm{~kg} / \mathrm{m}^{3} \mathrm{and} 2633$ $\mathrm{kg} / \mathrm{m}^{3}$. It was observed that with the increase in the fiber ratio, the unit weight values also increased. According to the literature, the use of fibers in different ratios changes the dry unit weights of the samples (Canbay, 2014; Ipek \& Aksu, 2019). The curing methods did not have a significant effect on the dry unit weight values of the samples.

\section{Ultrasonic pulse velocity}

Although the UPV value was expected to increase with the increase in fiber content, due to the high density of the steel fiber, no such result was observed in the experimental studies. Similar results were seen in Köroglu and Ashour's studies 
(Köroglu \& Ashour, 2019). On the contrary, although the UPV value of the slurry used in the preparation of the samples was $4851 \mathrm{~m} / \mathrm{s}$, the UPV value of the SIFCON prepared using the same slurry decreased and varied between $3918 \mathrm{~m} / \mathrm{s}$ and $4482 \mathrm{~m} / \mathrm{s}$. This was believed to be due to the increased fiber-matrix interface gaps as a result of the high fiber content. It was seen that fiber type and curing method did not have a significant effect on UPV value. The reason for this was thought to be due to the compact structure of the SIFCON mixtures.

\section{Flexural strength and fracture toughness}

The flexural strength of the samples varied between 19.69 MPa and 38.28 MPa depending on the effect of the different curing methods applied. Load-deflection graphs were drawn with the data obtained the experiments. Accordingly, the fracture toughness values of the samples were calculated and found to range from $14.54 \mathrm{Nm}$ to $46.01 \mathrm{Nm}$. The highest flexural strength and fracture toughness values belonged to the S55-8 coded sample, which had been subjected to the standard curing method and had an aspect ratio of 55 (38.28 MPa) and a fiber amount of $8 \%(46.01 \mathrm{Nm})$. The loaddeflection graph of sample S55-8 is given in Figure 3. After the flexural strength reached the highest value, deformation started to increase and breaking occurred by separating the steel fibers from the matrix structure.

Figure 3. Load-deflection graph of sample S55-8. (Self-Elaboration).

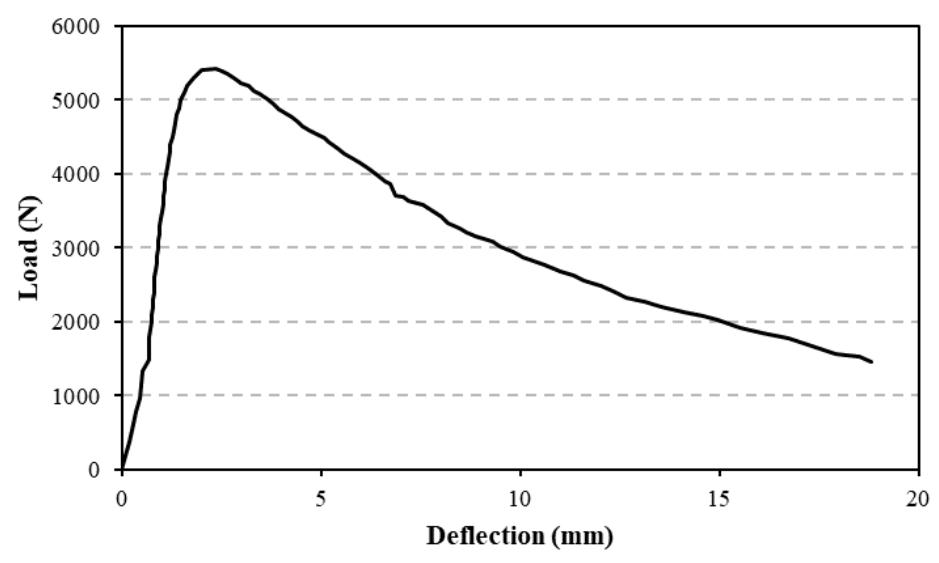

The effect of the amount of fiber on flexural strength and fracture toughness is presented in Figure 4 . When Figure 4 is examined, it can be seen that the samples with a fiber amount of $8 \%$ had higher flexural strength and fracture toughness value. As stated in the literature, with the increasing amount of fiber, the tensile stresses on the sample are mostly shared by the fiber, therefore, the flexural strength and fracture toughness of the samples increase (Sengul, 2018; Ipek et al., 2012; Ipek et al., 2014; Yan et al., 2002; Yazıcı et al., 2006; Farnam et al., 2010).

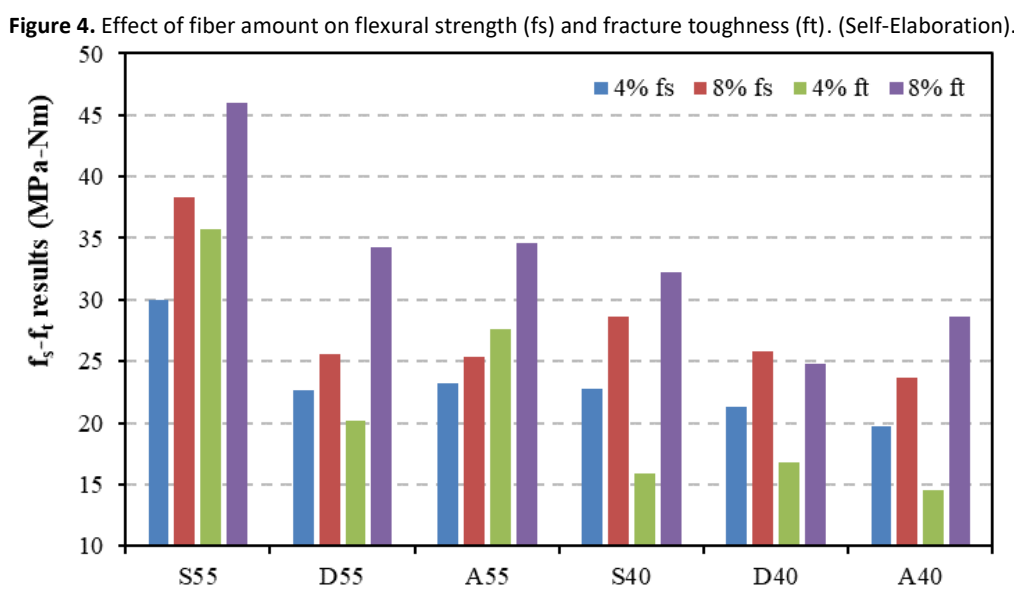

The effect of the curing methods on the flexural strength and fracture toughness of the samples are given in Figure 5. In both fiber types used in the study, the highest flexural strength and fracture toughness values were achieved in the samples exposed to the standard curing method. It was determined that this was due to the stronger adherence between the fiber and the matrix, as the hydration reactions were largely realized due to the standard curing. The load deflection graphs of the samples exposed to the standard curing, dry curing and accelerated curing methods are presented in Figures 6, 7 and 8, respectively. 
There was no significant relationship between the flexural strength of the samples subjected to accelerated curing and the flexural strength of the samples subjected to dry curing, however similar strength values were obtained with both curing methods. The values obtained in 28 days with the dry curing method were reached with the accelerated curing method in a shorter time. It is known that curing methods affect the strength values of concrete. In fibrous concretes, the bond strength between fiber and matrix increases as the curing conditions improve. According to the literature, the highest strengths in fibrous concretes were obtained in samples exposed to the standard curing method (Liu et al., 2018; Tuyan \& Yazıcı, 2012; Yeih \& Chang, 2019). In this context, the accelerated curing method should be evaluated in prefabricated productions where high resistance values are required in a short amount of time. This is important considering that the SIFCON manufacturing technique is more suitable for prefabricated productions.

Figure 5. The effect of curing method on flexural strength ( $\mathrm{fs}$ ) and fracture toughness (ft). (Self-Elaboration).

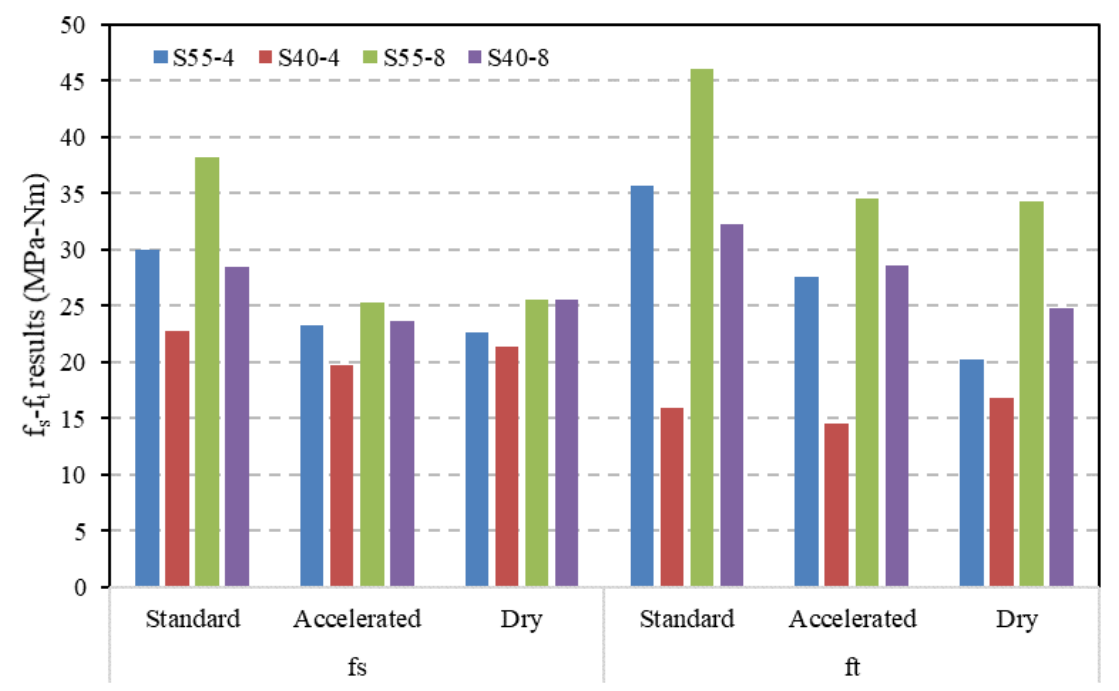

Figure 6. Load-deflection relationship of the samples subjected to the standard curing method. (Self-Elaboration).
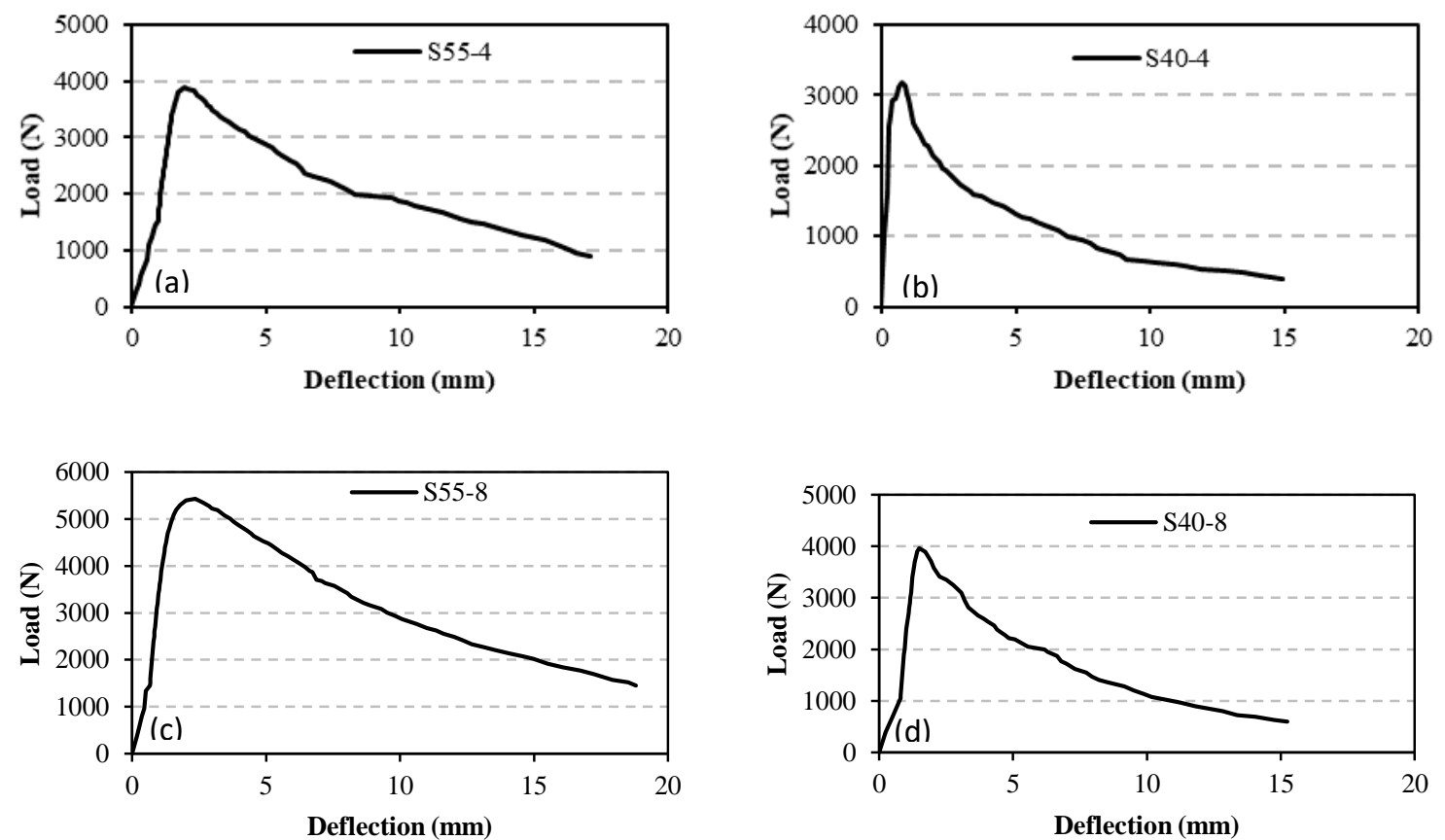

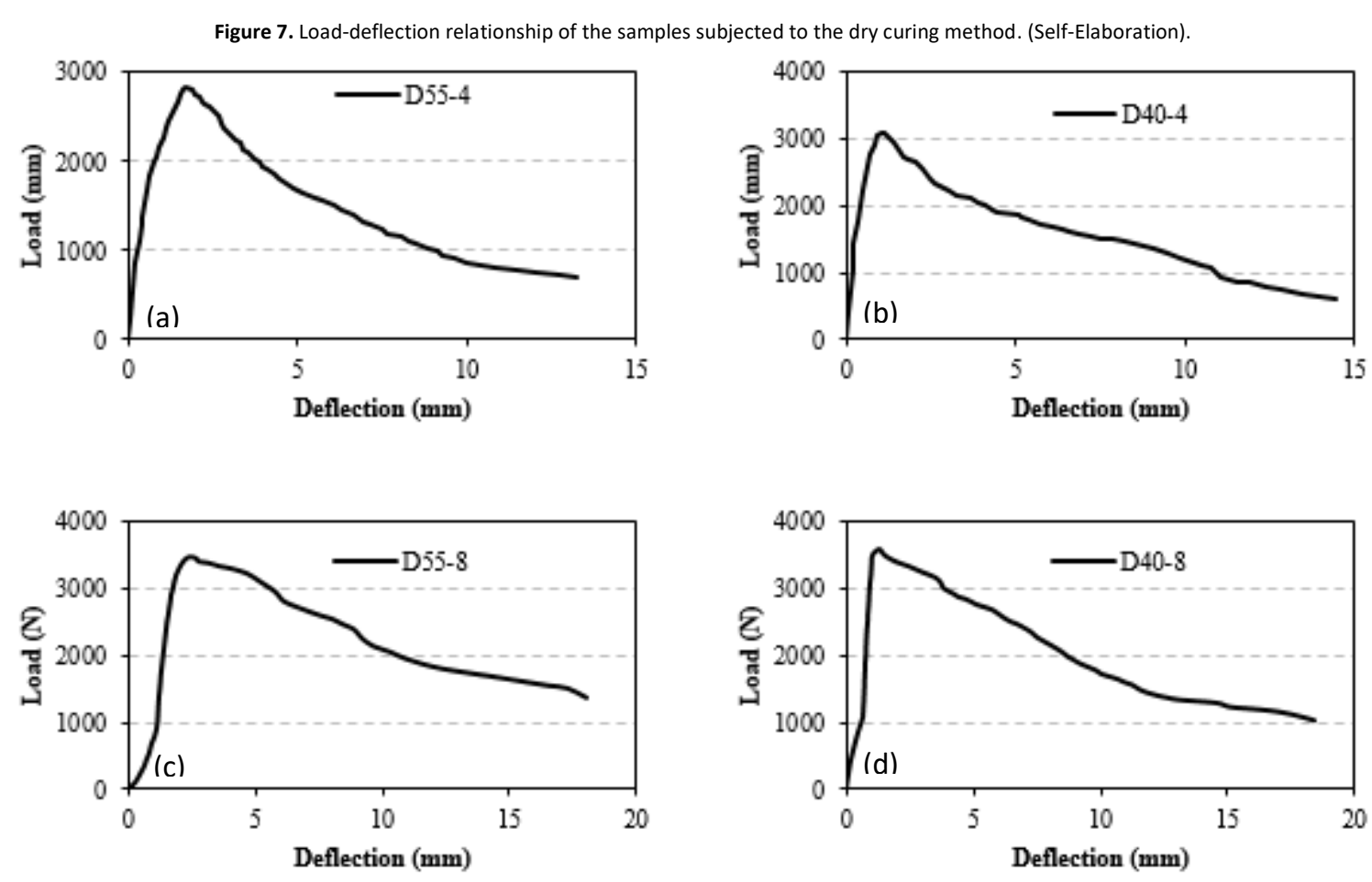

Figure 8. Load-deflection relationship of the samples subjected to the accelerated curing method. (Self-Elaboration).
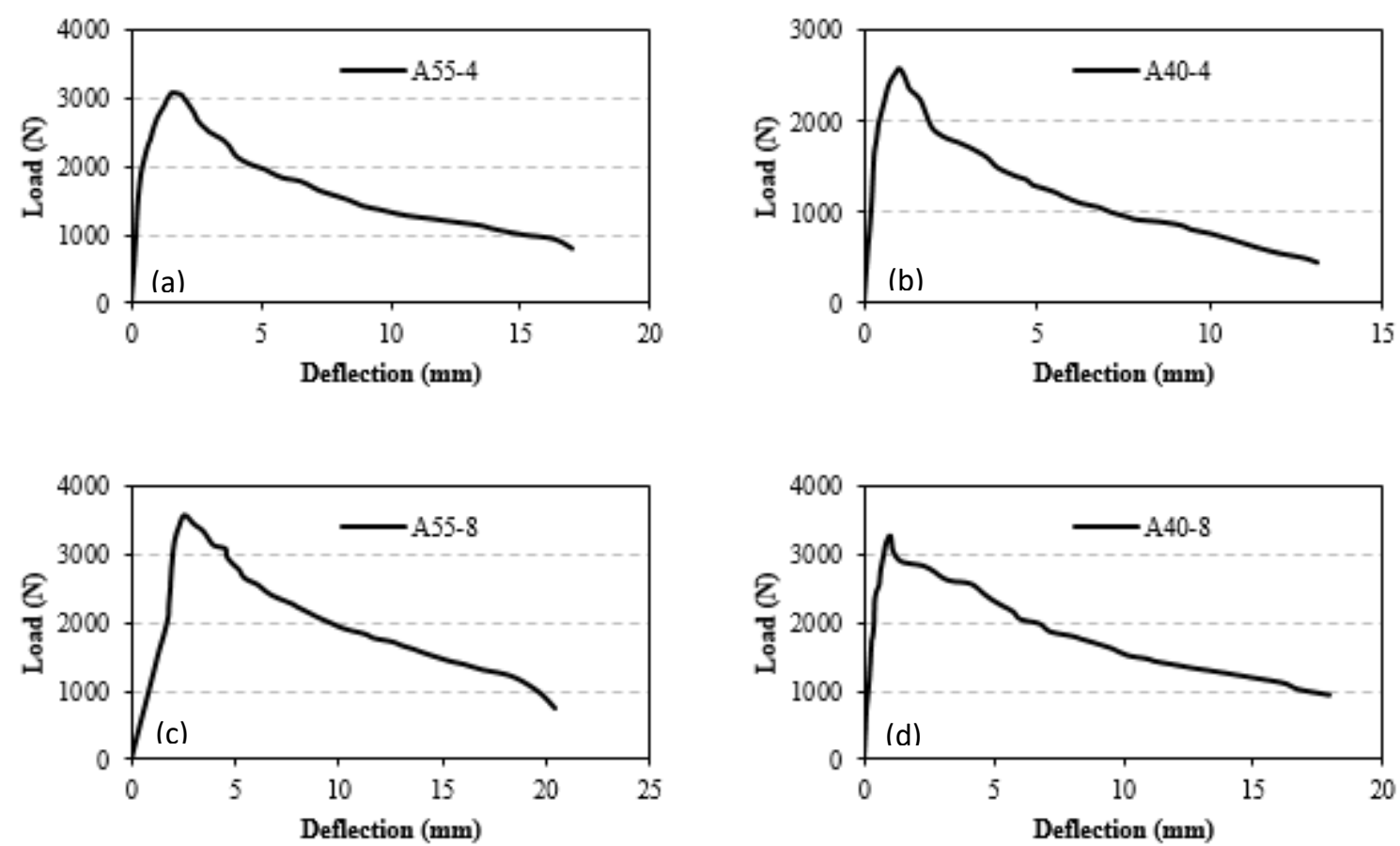

Sudden failure did not occur at high loads. The increasing amount of deflection in the samples including large amounts of fiber indicated gradual failure. The relationships between the flexural strength values found after the standard and accelerated curing methods were applied to the samples are given in Figure 9. It was observed that there was a strong relationship between the flexural strengths obtained in both curing methods with a correlation coefficient of 0.86 .

The flexural strength of the samples that were subjected to the standard curing method were measured at the end of 28 days. The flexural strength of the samples subjected to the accelerated curing method were measured after the samples were demolded and then cured at boiling temperature for 3.5 hours. When the flexural strength of the samples subjected to the accelerated curing method were compared with those of the samples subjected to the standard curing method, it was determined that the ratios obtained varied between 0.66 and 0.86 . Considering the production demand 
and strength properties of special works requiring mass production, it is possible to apply the accelerated curing method.

Figure 9. The relationship between standard and accelerated curing on flexural strength. (Self-Elaboration).

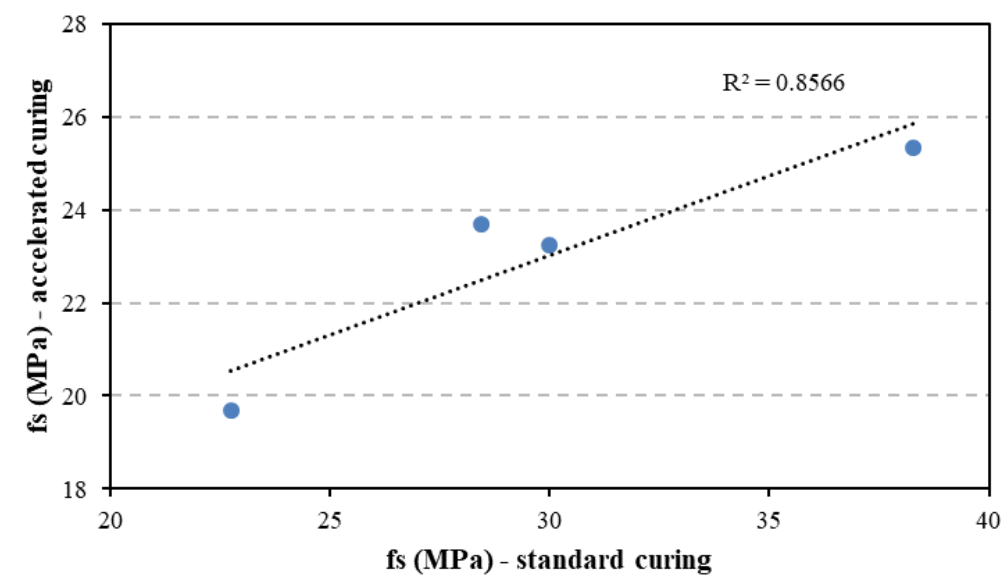

The relationships between the flexural strength and fracture toughness of the samples are given in Figure 10 . It was observed that there was a linear relationship between the fracture toughness of the SIFCON samples and the flexural strength with a correlation coefficient of 0.78 . When the obtained load deflection curves were examined, it was determined that flexural strength and fracture toughness were related. It was seen that the fracture toughness of the samples including high amounts of steel fiber increased in accordance with the increase in flexural strength.

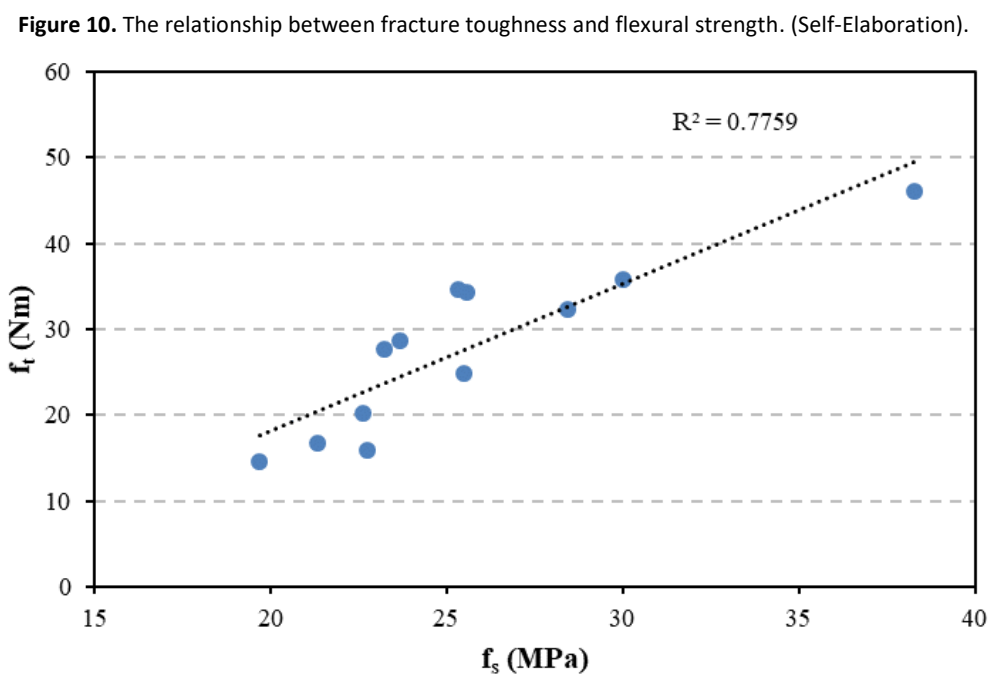

\section{Compressive strength}

When Table 5 is examined, it can be seen that the compressive strength values of the samples varied between 66.38 $\mathrm{MPa}$ and $110.55 \mathrm{MPa}$. The effects of the curing methods on the compressive strength of the samples with a steel fiber aspect ratio of 55 and 40 are given in Figure 11. The curing methods had similar effects on the compressive strength for both types of fiber. It was observed that the compressive strength values ranged from $96.25 \mathrm{MPa}$ to $110.55 \mathrm{MPa}$ in the samples subjected to the standard curing method, between 66.38 MPa and 73.43 MPa in the samples subjected to the accelerated curing method and between 76.10 MPa and 100.00 MPa in the samples subjected to the dry curing method. The highest compressive strength was determined in the samples subjected to the standard curing method, then those subjected to the dry curing method and the lowest values were determined in the samples subjected to the accelerated curing method. 
Figure 11. The effects of the curing methods on compressive strength. (Self-Elaboration).
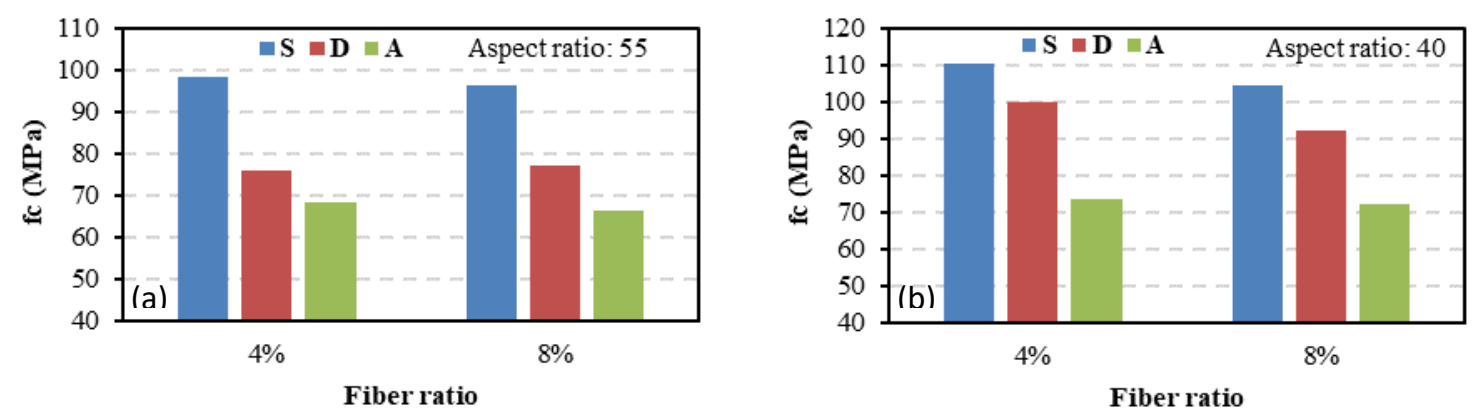

The effects of aspect ratio on the compressive strength is presented in Figure 12. It can be seen from the figure that the compressive strength values of the samples with an aspect ratio of 55 were lower than those with an aspect ratio of 40 . This was thought to be a result of the fact that there was a greater amount of fibers in the samples that were prepared with fibers that had an aspect ratio of 55 . The increase in the amount of steel fiber in the mixture causes more fibermatrix interface to occur and this leads to a decrease in the strength value.

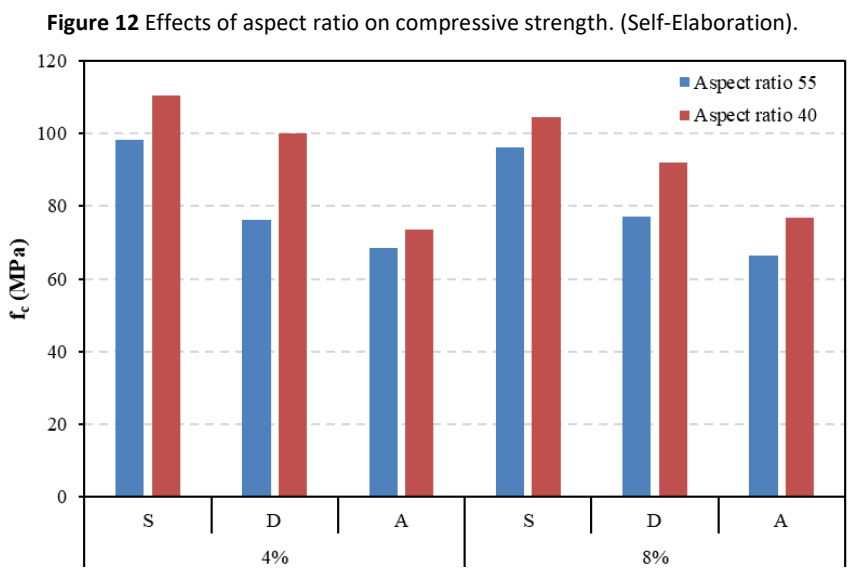

For both aspect ratios used in the mixtures, it was observed that the compressive strength values obtained when the fiber amount was $4 \%$ were higher than the values obtained when the fiber amount was $8 \%$. The reason for this was that as the fiber amount increases, the interface between fiber and matrix increase, which in turn causes an increase in the defective areas. It was thought that the amount of void in the mixture increased as the fiber content used increased. Ipek et al. (2014) determined that there were water and closed air spaces in SIFCON and that these spaces accumulated at the fiber and slurry interface. They stated that this adversely affected the adherence between fiber and slurry and, thus, decreased the strength. Wecharatana and Lin (1992) reported that compressive strength was not affected despite the increase in the fiber amount with increased flexural strength and fracture toughness (Ipek \& Aksu, 2019).

The relationships between the compressive strength of the samples subjected to the standard and accelerated methods are presented in Figure 13. It was observed that there was a linear relationship between the compressive strengths obtained after the standard and accelerated curing methods were applied, with a correlation coefficient of 0.9286 . The compressive strength values obtained with the accelerated curing method were approximately $68 \%$ of the values obtained with the standard curing method. Similar results were obtained in the literature (Kurbetçi \& Öztekin, 2004). 
Figure 13. The relationship between standard and accelerated curing on $\mathrm{fc}$. (Self-Elaboration).

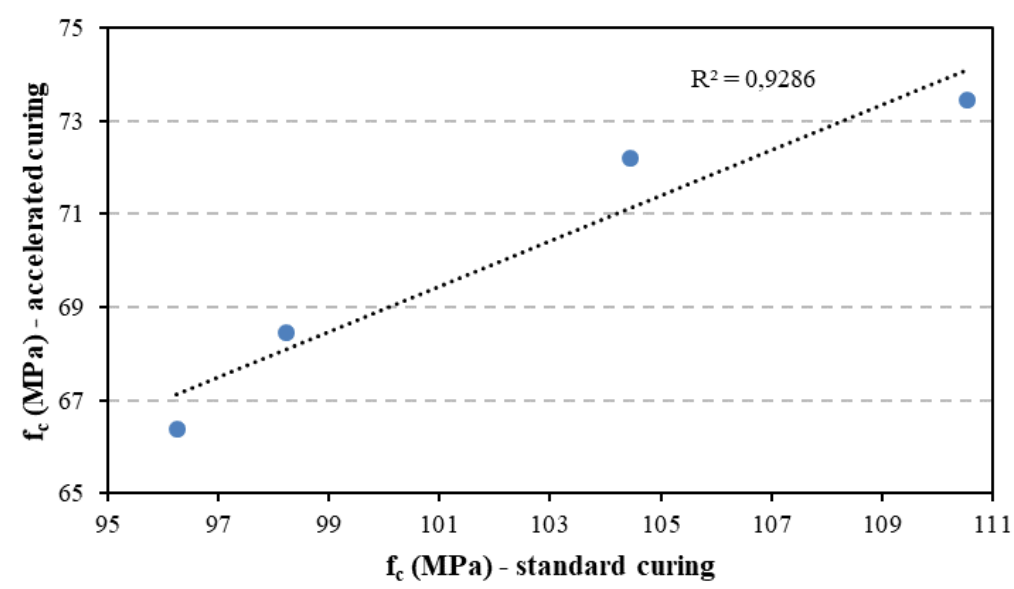

No significant relationship could be established between the UPV and the compressive strength of the samples obtained with different curing methods. It was thought that, this was due to the fact that the void structures of the samples prepared in fluid consistency were similar to each other.

\section{Impact resistance}

The impact resistance of the samples was determined by measuring the indentation amounts that occurred at the end of 2500 drops on $64 \times 150 \mathrm{~mm}$ cylinder samples. The indentation amounts were determined by using the Brinell hardness test method, which is applied to measure the hardness of metals. The circular indentations formed on the SIFCON samples can be seen in Figure 14.

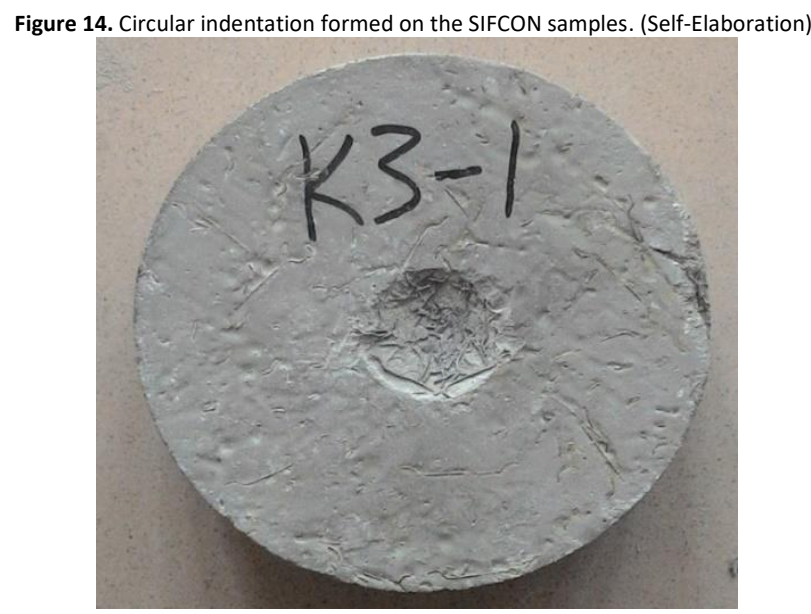

It was observed that the rate of steel fiber significantly influenced impact resistance. It was determined in all of the samples that the amount of indentation decreased with the increase of the steel fiber ratio. This improvement in impact resistance was found to be between $11 \%$ and $31 \%$ and varied according to fiber type and curing method. The reason for this was thought to be due to the homogeneous dispersion of the impact effect applied on the sample with the increase in the amount of steel fiber. It is stated in the literature that the impact resistance of SIFCON increases with the increase in the amount of fiber (Elavarasi \& Saravana, 2018; Rao et al., 2010; Rao et al., 2008).

It was seen that curing method had a significant effect on the impact resistance of the samples with an $8 \%$ steel fiber amount. The samples subjected to the standard curing method had the highest impact resistance, while the samples subject to the accelerated curing method had the lowest impact resistance. This result was similar to the compressive strength results. The impact resistance values of the samples with a $4 \%$ steel fiber amount were found to be very close to each other, however the mentioned situation was not valid for the samples with an $8 \%$ fiber amount.

It was observed that the impact strength of the samples produced with steel fibers with an aspect ratio of 55 was higher than those produced with steel fibers with an aspect ratio of 40 . This increase in impact resistance varied between $3 \%$ and $16 \%$. It was thought that this was due to the fact that there was a greater number of steel fibers in the sample with an aspect ratio of 55 and that these fibers emitted the impact effect. The fibers, which were more tightly formed in the 
sample were able to transfer the impact effect onto the other fibers. For this reason, the impact strength of the samples increased. Among the samples, only the crack formed on the lower surface of D40-4 sample that had the lowest impact resistance (Figure 15).

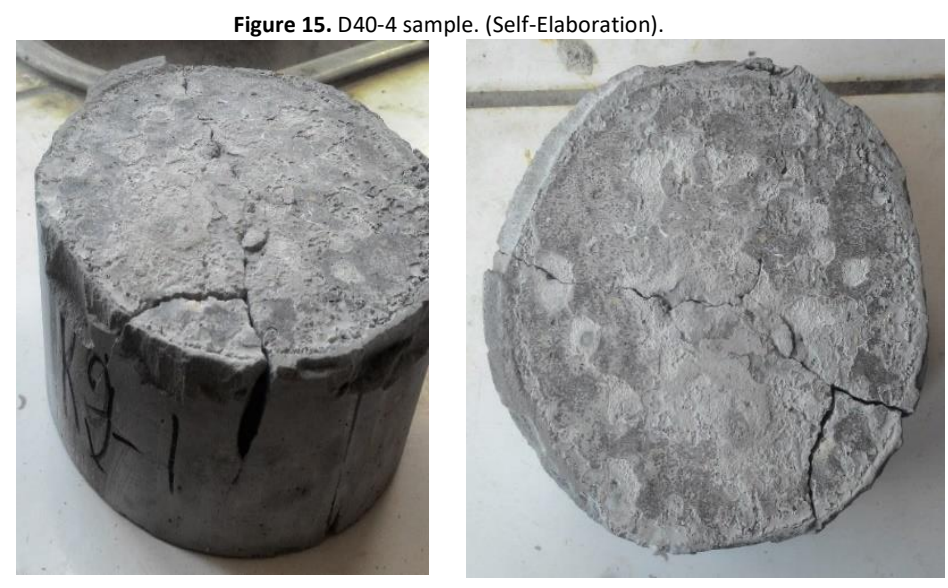

\section{Capillary water absorption}

The capillary water absorption coefficients were between $0.0159-0.0384 \mathrm{~cm} / \mathrm{s}$ in the samples subjected to the standard curing method, $0.0503-0.1425 \mathrm{~cm} / \mathrm{s}$ in the samples subjected to the dry curing method and $0.0337-0.0420 \mathrm{~cm} / \mathrm{s}$ in the samples subjected to the accelerated curing method.

It was observed that the capillary water absorption amount of the samples subjected with the dry curing method had the highest value. The capillary water absorption coefficients of the samples subjected to the standard and accelerated curing methods were found to be close to each other. According to the literature, the hydration mechanisms of the samples do not realize very well in the dry curing environment. This was explained by the disappearance of the water in the capillary spaces in the samples cured by the dry curing method (Güneyisi et al., 2009). It was also stated in the literature that curing method is highly effective on the water absorption properties of concrete (Taşdemir, 2003; Sakai et al., 2017; Liu et al., 2018). It was observed that the capillary water absorption coefficients of the samples produced in the present study decreased with the increase of steel fiber ratio. The reason for this was thought to be the reduction of the capillary spaces due to the decrease in the slurry volume. It was observed that fiber type did not have a significant effect on the capillary water absorption amount of the samples.

\section{Conclusions}

The following conclusions can be drawn from the results of the present study:

- The highest flexural strength and fracture toughness values were observed in the SIFCON samples that were subjected to the standard curing method and had a fiber amount of $8 \%$. The flexural strength values of the SIFCON samples with an aspect ratio of 55 were higher than those with an aspect ratio of 40 .

- In contrast to the flexural strength values, the compressive strength values of the SIFCON samples with an aspect ratio of 55 were lower.

- An increase in fiber amount caused a decrease in compressive strength values, as the interface between fiber and matrix increased, which in turn caused an increase in the defective areas.

- The compressive strength values of the SIFCON samples subjected to the accelerated curing method reached approximately $68 \%$ of the compressive strength values of the samples subjected to the standard curing method. This result showed that the SIFCON composites produced with the accelerated curing method can be an alternative in applications that require mass production.

- The impact resistance of the SIFCON samples with a $4 \%$ fiber amount was higher than those with an $8 \%$ fiber amount.

- The curing method had an effect on the capillary water absorption coefficient of the SIFCON samples. The maximum amount of capillary water absorption was measured in the samples subjected to the dry curing method. 
The authors would like to thank the Scientific Research and Projects Unit of Niğde Ömer Halisdemir University for their support (Project number: FEB 2018/01-BAGEP).

American Concrete Institute (ACl) Committee 544. (1988). "Measurement of properties of fibre reinforced concrete.". ACl Material Journal, 85(6), 583-593.

ASTM C1018. (1989). Standard test method for flexural toughness and first crack strongth of fiber reinforced concrete. American Society for Testing and Materials, USA.

Bayramov, F., Taşdemir, C., \& Taşdemir, M.A., Optimum design of cement-based composite materials using statistical response surface method. Fifth International Congress on Advances in Civil Engineering, Istanbul Technical University, Istanbul, Turkey, 2002, pp. 725-734

Beglarigale, A., Yalçınkaya, Ç., Yiğiter, H., \& Yazıcı, H. (2016). Flexural performance of SIFCON composites subjected to high temperature. Construction and Building Materials, 104, 99-108. https://doi.org/10.1016/j.conbuildmat.2015.12.034

Canbay, M. (2014). The effect of steel and polypropylene fibers as combination and single use sifcon. Master thesis, Sakarya University, Institue of Natural Science, 20-60.

Elavarasi, D., \& Saravana Raja Mohan, K. (2018). On low-velocity impact response of SIFCON slabs under drop hammer impact loading. Construction and Building Materials, 160, 127-135. https://doi.org/10.1016/j.conbuildmat.2017.11.013

Farnam, Y., Moosavi, M., Shekarchi, M., Babanajad, S. K., \& Bagherzadeh, A. (2010). Behaviour of slurry infiltrated fibre concrete (SIFCON) under triaxial compression. Cement and Concrete Research, 40(11), 1571-1581. https://doi.org/10.1016/j.cemconres.2010.06.009

Güneyisi, E., Gesoğlu, M., Özturan, T., \& Özbay, E. (2009). Estimation of chloride permeability of concretes by empirical modeling: Considering effects of cement type, curing condition and age. Construction and Building Materials, 23(1), 469-481. https://doi.org/10.1016/j.conbuildmat.2007.10.022

Hajar, Z., Lecointre, D., Simon, \& A. Petitjean, J. (2004). Design and construction of the world first ultra-high performance concrete road bridges. International Symposium on Ultra High Performance, Kassel, Germany, 13-15 September, 2004.

Homrich, J. R., \& Naaman, A. E. (1987). Stress-strain properties of SIFCON in compression. Fiber Reinforced Concrete Properties and Applications, SP105, ACI SP, 283-304.

Ipek, M., \& Aksu, M. (2019). The effect of different types of fiber on flexure strength and fracture toughness in SIFCON. Construction and Building Materials, 214, 207-218. https://doi.org/10.1016/j.conbuildmat.2019.04.055

Ipek, M., Aksu, M., Yılmaz, K., \& Uysal, M. (2014). The effect of pre-setting pressure on the flexural strength and fracture toughness of SIFCON during the setting phase. Construction and Building Materials, 66, 515-521. https://doi.org/10.1016/j.conbuildmat.2014.04.107

Ipek, M., Yılmaz, K., \& Uysal, M. (2012). The effect of pre-setting pressure applied flexural strength and fracture toughness of reactive powder concrete during the setting phase. Construction and Building Materials, 26, 459-465. https://doi.org/10.1016/j.conbuildmat.2011.06.045

Jung, H., Park, S., Kim, S., \& Park, C. (2017). Performance of SIFCON based HPFRCC under field blast load. Procedia Engineering, 210, $401-408$. https://doi.org/10.1016/j.proeng.2017.11.094

Köksal, F., Altun, F., Yiğit, İ., \& Şahin, Y. (2008). Combined effect of silica fume and steel fiber on the mechanical properties of high strength concrete. Construction and Building Materials, 22, 1874-1880. https://doi.org/10.1016/j.conbuildmat.2007.04.017

Köroglu, M. A., \& Ashour, A. (2019). Mechanical properties of self-compacting concrete with recycled bead wires. Revista de la construcción, 18(3), 501-512. https://doi.org/10.7764/RDLC.18.3.501

Kurbetçi, Ş., \& Öztekin, E. (2004). Estimation of compressive strength of concrete using the modified warm water method. Chamber of Civil Engineers Technical Journal, 211, 3145-3153.

Lankard, D. R. (1984). Slurry Infiltrated Fiber Concrete (SIFCON): properties and applications, MRS Proc. 42, 277.

Lankard, D. R., \& Newell, J. K. (1984). Preparation of highly reinforced steel fiber reinforced concrete composites. Fiber reinforced concreteinternational symposium, 287-306, ACI SP-81, American Concrete Institute, Detroit, United States.

Lin, C., Kayali, O., Morozov, E. V., \& Sharp, D. J. (2014). Influence of fibre type on flexural behaviour of self-compacting fibre reinforced cementitious composites. Cement \& Concrete Composites, 51, 27-37.

Liu, B., Luo, G., \& Xie, Y. (2018). Effect of curing conditions on the permeability of concrete with high volume mineral admixtures. Construction and Building Materials, 167, 359-371. https://doi.org/10.1016/j.conbuildmat.2018.01.190

Murakami, H., \& Zeng, J. Y. (1998). Experimental and analytical study of SIMCON tension members, Mechanics of Materials, 28 (1-4), $181-195$.

Naaman, A. E., Otter, D., \& Najm, H. (1991). Elastic modulus of SIFCON in tension and compression. ACI Material Journal, 88(6), 603-612.

Naaman, A. E., Otter, D., \& Najm, H. (1992a). Elastic modulus of SIFCON in tension and compression. ACI Material Journal, 88 (6), $603-613$.

Naaman, A. E., Reinhardt, H. W., \& Fritz, C. (1992b). Reinforced concrete beams with a SIFCON matrix. ACI Structural Journal,89(1), 79-88. 
Naaman, A. E., Wight, J. K., \& Abdou, H. (1987). SIFCON connections for seismic resistant frames. Concrete International, 9(11), 34-39.

Rao, H. S., \& Ramana, N. V. (2005). Behaviour of slurry infiltrated fibrous concrete (SIFCON) on simply supported two way slabs in flexure. Indian Journal of Engineering and Materials Sciences, 12, 427-433.

Rao, H. S., Ramana, N. V., \& Gnaneswar, K. (2008). Behaviour of steel reinforced slurry infiltrated fibrous concrete (SIFCON) two way slabs in punching shear. Indian Journal of Engineering and Materials Sciences, 15, 334-342.

Rao, H. S., Vaishali G. G., Ramana, N.V., \& Gnaneswar, K. (2010). Response of SIFCON two-way slabs under impact loading. International Journal of Impact Engineering, 37(4), 452-458.

Sakai, Y., Yokoyama, Y., \& Kishi, T. (2017). Relationship among the permeation rate of water into concrete, the mix design, curing, and the degree of drying. Journal of Advanced Concrete Technology, 15(10), 595-602. https://doi.org/10.3151/jact.15.595

Schneider, B. (1992). Development of SIFCON through Applications. In High Performance Fiber Reinforced Cement Composites (pp. 177-194). Rilem.

Sengul, O. (2018). Mechanical properties of slurry infiltrated fiber concrete produced with waste steel fibers. Construction and Building Materials, 186, 1082-1091. https://doi.org/10.1016/j.conbuildmat.2018.08.042

Shan, L., \& Zhang, L. (2014). Experimental study on mechanical properties of steel and polypropylene fiber-reinforced concrete. In Applied Mechanics and Materials (Vol. 584, pp. 1355-1361). Trans Tech Publications Ltd.

Shannag, M. J., Brincker, R., \& Hansen, W. (1997). Pullout behavior of steel fibers from cement-based composites. Cement and Concrete Research, 27(6), 925-936. https://doi.org/10.1016/S0008-8846(97)00061-6

Stiel, T., Karihaloo, B.L., \& Fehling, E. (2004). Effect of casting direction on the mechanical properties of CARDIFRC, in: International Symposium on Ultra High Performance, 481-493, Kassel, Germany, 13-15 September, 2004.

Taşdemir, C. (2003). Combined effects of mineral admixtures and curing conditions on the sorptivity coefficient of concrete. Cement and Concrete Research, 33(10), 1637-1642. https://doi.org/10.1016/S0008-8846(03)00112-1

Taşdemir, M. A., Bayramov, F., Kocatürk, A.N., \& Yerlikaya, M. (2004). New developments in concrete design according to performance, National Concrete Congress, 1-34, İstanbul, Turkey, 2004

Thirugnanam, G. S., Govindan, P., \& Sethurathnam, A. (2001). Ductile behavior of SIFCON structural members. J. Structural Engineering, $28(1)$, 27-32.

Topçu, I. B., \& Boğa, A. R. (2005). Use of fly ash and steel fibers in concrete and concrete pipes. Journal of Engineering and Architecture Faculty of Eskisehir Osmangazi University, 18 (2), 1-14.

TS 3323. (2012). Concrete-making, accelerated curing and testing concrete compression test specimens. Turkish Standards Institution, Ankara.

TS EN 1015-3/A2. (2007). Methods of test for mortar for masonry-Part 3: Determination of consistence of fresh mortar (by flow table). Turkish Standards Institution, Ankara.

TS EN 12390-3. (2010). Testing hardened concrete-Part 3: Compressive strength of test specimens. Turkish Standards Institution, Ankara.

TS EN 14651. (2008). Test method for metallic fibre concrete-Measuring the flexural tensile strength (limit of proportionality (LOP), residual). Turkish Standards Institution, Ankara.

TS EN 14889-1. (2016). Fibres for concrete-Part 1: Steel fibres - Definitions, specifications and conformity. Turkish Standards Institution, Ankara.

TS EN 15167-1. (2006). Ground granulated blast furnace slag for use in concrete, mortar and grout-Part 1: Definitions, specifications and conformity criteria, Turkish Standards Institution, Ankara.

TS EN 197-1. (2012). Cement-Part 1: Composition, specification and conformity criteria for common cements, Turkish Standards Institution, Ankara.

TS EN 772-11. (2012). Methods of test for masonry units-Part 11: Determination of water absorption of aggregate concrete, autoclaved aerated concrete, manufactured stone and natural stone masonry units due to capillary action and the initial rate of water absorption of clay masonry units. Turkish Standards Institution, Ankara.

TS EN 934-2. (2013). Admixtures for concrete, mortar and grout-Part 2: Concrete admixtures-Definitions, requirements, conformity, marking and labelling. Turkish Standards Institution, Ankara.

Tuyan, M., \& YazıcI, H. (2012). Pull-out behavior of single steel fiber from SIFCON matrix. Construction and Building Materials, 35 , 571-577. https://doi.org/10.1016/j.conbuildmat.2012.04.110

Wang, M. L. (1994). Constitutive properties of SIFCON. Proceeding, workshop on fibre reinforced cement and concrete, 237-255, Sheffield, England, July 28-30, 1994.

Wecharatana, M., \& Lin, S. (1992). Tensile properties of high performance fiber reinforced concrete. High Performance Fiber Reinforced Cement Composites, London, England, 248-258.

Wood, B. T. (2000). Use of slurry infiltrated fiber concrete (SIFCON) in hinge regions for earthquake resistant structures, PhD Thesis, North Carolina State Univ., Civil Engineering, Raleigh.

Yan, A., Wu, K., \& Zhang, X. (2002). A quantitative study on the surface crack pattern of concrete with high concent of steel fiber. Cement and Concrete Research, 32(9), 1371-1375. https://doi.org/10.1016/S0008-8846(02)00788-3

Yazıcı, H., Aydın, S., Yiğiter, H., Yardımcı, M. Y., \& Alptuna, G. (2010). Improvement on SIFCON performance by fiber orientation and high-volume mineral admixtures. Journal of Materials in Civil Engineering, 22(11), 1093-1011. https://doi.org/10.1061/(ASCE)MT.1943-5533.0000114 
Yazıcı, H., Yiğiter, H., Aydın, S., \& Baradan, B. (2006). Autoclaved SIFCON with high volume Class C fly ash binder phase. Cement and Concrete Research, 36(3), 481-486. https://doi.org/10.1016/j.cemconres.2005.10.002

Yeih, W., \& Chang, J. J. (2019). The influences of cement type and curing condition on properties of pervious concrete made with electric arc furnace slag as aggregates. Construction and Building Materials, 197, 813-820. https://doi.org/10.1016/j.conbuildmat.2018.08.178

Yoo, D-Y., Kim, M-J., Kim, S. Ryu, G-S., \& Koh, K-T. (2018). Effects of mix proportion and curing condition on shrinkage behavior of HPFRCCs with silica fume and blast furnace slag. Construction and Building Materials, 166, 241-256. https://doi.org/10.1016/j.conbuildmat.2018.01.126

Yeih, W., \& Chang, J. J. (2019). The influences of cement type and curing condition on properties of pervious concrete made with electric arc furnace slag as aggregates. Construction and Building Materials, 197, 813-820.

Yoo, D-Y., Kim, M-J., Kim, S. Ryu, G-S., \& Koh, K-T. (2018). Effects of mix proportion and curing condition on shrinkage behavior of HPFRCCs with silica fume and blast furnace slag. Construction and Building Materials, 166, 241-256. 